\title{
Infusional \\ Fluorouracil/Leucovorin/Bevacizumab Regimen
}

National Cancer Institute

\section{Source}

National Cancer Institute. Infusional Fluorouracil/Leucovorin/Bevacizumab Regimen. NCI Thesaurus. Code C136257.

A chemoimmunotherapy regimen consisting of infusional fluorouracil, leucovorin and bevacizumab that is used for the treatment of colon cancer. 